\title{
Cognitive functioning in bulimia: Comparison with depression
}

\author{
WILLIAM W. BEATTY \\ The Neuropsychiatric Research Institute, Fargo, North Dakota \\ and North Dakota State University, Fargo, North Dakota \\ STEPHEN A. WONDERLICH \\ University of North Dakota School of Medicine, Fargo, North Dakota \\ and Fargo Clinic Eating Disorders Program, Fargo, North Dakota \\ R. DENNIS STATON \\ University of North Dakota School of Medicine, Fargo, North Dakota \\ and Fargo Veterans Administration Medical Center, Fargo, North Dakota \\ and \\ LOIS A. TERNES \\ North Dakota State University, Fargo, North Dakota
}

\begin{abstract}
The neuropsychological test performance of groups of female outpatients with major depression or bulimia nervosa was examined. Compared to normal controls, both groups were impaired in learning and recalling a list of unrelated words and in generating the names of famous people, and both groups showed elevated scores on the Beck Depression Inventory and the State and Trait Anxiety Scales. In addition, the bulimic but not the depressed sample made more rule violations than did controls on a design-fluency task. Both patient groups generated normal numbers of correct responses on letter, category, and design-fluency tests; they also performed normally on the Symbol Digit Modalities Test, a version of the Brown-Peterson short-term memory test, and on a test of verbal recognition memory. Thus, similar focal neuropsychological deficits can be demonstrated in outpatients with bulimia or depression. In addition, bulimia but not depression may be characterized by a previously unrecognized cognitive impairment: the tendency to violate task rules.
\end{abstract}

The occurrence of impairment of cognitive functioning during periods of major depression severe enough to require hospitalization is well documented. The most frequently reported impairments include psychomotor slowing (Brand \& Jolles, 1987; Hart \& Kwentus, 1987; Raskin, Friedman, \& DiMascio, 1982), deficits in attention and concentration (Breslow, Kocsis, \& Belkin, 1980; Stromgren, 1977) and in anterograde memory (Clev, Korin, Shapira, Kugelmass, \& Lerer, 1986; Fromm \& Schopflocher, 1984; Raskin et al., 1982; Weingartner, Cohen, Murphy, Martello, \& Gerdt, 1981), and deficits on tasks that require hypothesis generation or set shifting (Fromm \& Schopflocher, 1984; Savard, Rey, \& Post, 1981; Silberman, Weingartner, \& Post, 1983). Cognitive performance usually improves after successful treatment of depression with either medication or electroconvulsive therapy, although performance may not reach levels attained by nondepressed controls (Frith et al., 1983;

We thank Janet Bruellman, Jill Gravely, Bill Whiteman, Teresa Heidt, and Kara Underwood, who assisted in testing subjects, and Scott Farmer, James Council, and Richard Stadter, who allowed us to study their patients. Please send correspondence or requests to R. Dennis Staton, Psychiatry Service 116A, Fargo VA Medical Center, Fargo, ND 58102.
Fromm \& Schopflocher, 1984; Staton, Wilson, \& Brumback, 1981; Sternberg \& Jarvik, 1976).

Neuropsychological deficits are only infrequently reported in bulimia (Heilbrun \& Bloomfield, 1986; McKay, Humphries, Allen, \& Clawson, 1986; Touyz, Beaumont, \& Johnstone, 1986), despite the fact that a high percentage of bulimics exhibit mild to moderate depression (see, e.g., Lee, Rush, \& Mitchell, 1985). One reason may be that most bulimics are treated as outpatients. Few studies of the cognitive function of depressed outpatients have been reported, and the available evidence suggests that such patients may not exhibit the impairments that have been described in studies of depressed inpatients. For example, Niederehe (1986) and Reisberg, Ferris, Georgotas, DeLeon, and Schneck (1982) found no evidence of memory impairment in samples of depressed outpatients. If depressed outpatients do exhibit few cognitive deficits, then depression-related cognitive impairment in bulimia would be expected to be uncommon, although the use of insensitive measures may be a factor as well. Direct comparison of bulimic and depressed outpatients with a suitable neuropsychological battery could resolve this issue, but, to our knowledge, such a study has not been reported. Our purpose in the present research was 
to compare the performance of bulimic and depressed outpatients on a battery of neuropsychological tests chosen to assess functions reported to be impaired in depressed inpatients.

\section{METHODS}

\section{Subjects}

The psychiatric subjects included 14 women who met the DSM-III-R criteria for a major depressive episode, and 32 women who met the criteria for bulimia nervosa. All subjects were carefully interviewed by psychiatric residents or trained research assistants, to confirm that the primary diagnosis was either major depression or bulimia. Subjects with current or past diagnoses of any psychotic disorder, alcohol abuse or dependence, primary anxiety disorders, neurological disease, learning disability, or current usage of psychotropic medications were excluded.

The depressed subjects were all seeking or receiving treatment at local mental health clinics. All were drug-free at the time of the study and awaiting initiation of antidepressant treatment. Twenty-eight of the bulimics were receiving treatment from an eating disorders clinic or mental health center. Four bulimics were college students recruited from another study and were not receiving treatment. None displayed the severe restricted eating patterns and weight loss that characterize a bulimicanorexic condition.

Forty-two female contols, who were 18-45 years old and had no history of eating disorders or affective illness, were recruited from the community. The younger subjects were students at North Dakota State University and received extra credit in introductory psychology courses as compensation. The older nonstudents were paid for their participation. The controls met the same exclusionary criteria as the patients.

\section{Materials and Procedures}

The subjects first completed the Beck Depression Inventory (BDI; Beck, Ward, Mendelson, Mock, \& Erbaugh, 1961) and the State-Trait Anxiety Scale (Spielberger, Gorsach, \& Lushene, 1970). Then the following cognitive measures were administered:

Symbol Digit Modalities Test. This test (SDMT; Smith, 1973) measures speed of processing novel information and is sensitive to impairments in attention and short-term memory. Subjects were shown a key with nine arbitrary geometric symbols printed above the digits 1-9. Below the key, symbols were printed in random order. The subjects were given $90 \mathrm{sec}$ to write the appropriate number below as many symbols as possible.

Fluency test: Letters. Subjects were allowed $60 \mathrm{sec}$ to say as many words as possible that began with the letter F. Proper names and minor variations in word endings were not allowed. The procedure was repeated with the letters $A$ and $S$.

Fluency test: Categories. Subjects were allowed $60 \mathrm{sec}$ each to name as many examples as possible of the following categories: animals, fruits, and parts of the body.

Fluency test: Famous people. Subjects were allowed $90 \mathrm{sec}$ to name as many famous people as possible. They were told that the people they named could be well known in any area, and they were given examples of possible areas (e.g., sports, politics) from which famous people might be generated. They were also told that the famous people could be living or dead. At the conclusion of the test, the examiner asked the subject to explain why persons named who were unknown to the examiner were famous. Like category fluency, fluency for famous people requires retrieval of information from semantic memory. Although not explicitly required by the task, subjects who generate many examples of famous people often appear to select a category (e.g., movie stars) and generate many exemplars from that category before shifting to another category. Because of this property, the test is arguably more effortful than category fluency in which the experimenter provides the category for the subject.

Fluency test: Design. Subjects were allowed 4 min to produce as many designs as possible that contained four and only four lines. They were told (and shown) that a circle, an arc, or a straight line counted as one line and that their drawings did not have to represent any real object. The number of correct designs produced and the number of rule violations (drawings containing fewer or more than four lines) were recorded.
Anterograde memory: Brown-Peterson short-term memory. On this test (STM), subjects were read a list of four unrelated words followed by a three-digit number, at the rate of 1 per second. Following a 15-sec retention interval filled with a distractor task (counting backwards by threes), they attempted to recall as many words as possible. Approximately $10 \mathrm{sec}$ later, the next trial began. Ten trials were given.

Anterograde memory: Free recall. Subjects were read a list of 14 unrelated neutral words at the rate of one word every $2 \mathrm{sec}$. Then they attempted to recall as many words as possible in any order. When a subject could not recall any more words, the list was read again with the words in a different order. Four such learning-recall trials were given. Thirty minutes later, delayed recall was measured. Immediately after the delayed recall trial, recognition memory for the same list was assessed. The subjects were read a list of 28 words (14 target words from the list and 14 distractors, matched to the targets in terms of frequency, meaningfulness, and imageability). After each word was read, the subjects responded "yes" if they believed the word was a target word from the list, or "no" if they believed that the word was not on the list. The retention interval was filled with tests of nonverbal functions.

\section{RESULTS}

Table 1 summarizes the demographic, psychometric, and cognitive findings. There were no significant differences among the three groups in years of education $[F(2,85)=1.91, p>.10]$, but the groups did differ in age $[F(2,85)=5.83, p<.01]$. Subsequent analyses showed that the depressed patients were older than the bulimics $[F(1,44)=15.58, p<.001]$, but neither of the patient groups differed significantly from controls $(F \mathrm{~s}<3.90$, ps $>.05)$. Since age was not significantly correlated with any cognitive variable $(r s<0.21$, $p s>.05)$, differences in age among the groups are of no importance in interpreting the cognitive data.

Table 1

Mean Performance (with Standard Deviations) on the Demographic Psychometric and Cognitive Variables

\begin{tabular}{|c|c|c|c|c|c|c|}
\hline & \multicolumn{2}{|c|}{ Controls } & \multicolumn{2}{|c|}{ Depressives } & \multicolumn{2}{|c|}{ Bulimics } \\
\hline & $M$ & $S D$ & $M$ & $S D$ & $M$ & $S D$ \\
\hline Age (years) & 24.6 & 7.6 & 29.2 & 7.1 & 21.9 & 5.2 \\
\hline Education (years) & & & .4 & 2.5 & 3.4 & 1.5 \\
\hline BDI & & 2 & .4 & 0.0 & 22.8 & 10.8 \\
\hline State anxiety & 29.7 & 7.0 & 54.3 & 12.6 & 46.2 & 13.1 \\
\hline Tra & 30.8 & 7.3 & 63.6 & 6.1 & 58.2 & 11.4 \\
\hline correct & 56.1 & 11.0 & 56.7 & 9.4 & 57.5 & 9.0 \\
\hline SD & 1.0 & 1 & 0.6 & 1.0 & 1.7 & 2.0 \\
\hline \multicolumn{7}{|c|}{ Fluency Tests } \\
\hline etter & 44.6 & 9.8 & 38.4 & 8.3 & 41.8 & 10.7 \\
\hline ies & 7 & 10.8 & 1.6 & 10.0 & 63.2 & 11.3 \\
\hline ople & 19.4 & 5.6 & $15.4 \dagger$ & 6.1 & $14.8 \dagger$ & 5.8 \\
\hline De & 26.7 & 9.6 & 27.6 & 13.8 & 26.8 & 12.3 \\
\hline Aun & 0 . & 1.6 & 05 & 1.1 & $2.1^{*}$ & 3.4 \\
\hline \multicolumn{7}{|c|}{ Anterograde Memory } \\
\hline STM & 25.3 & 6.6 & 22.1 & 6.6 & 25.1 & 7.6 \\
\hline Trial 1 & 7.1 & 1.7 & & 1.5 & $6.1^{*}$ & 1.5 \\
\hline Trial 2 & 9.4 & 1.7 & & 1.6 & 8.4* & 1.7 \\
\hline Trial 3 & 10.5 & 1.7 & $9.6^{*}$ & 1.8 & $9.4^{*}$ & 2.0 \\
\hline Trial 4 & 11.5 & 1.8 & $9.7^{*}$ & 1.9 & $10.0^{*}$ & 2.0 \\
\hline Delay & 10.3 & 1.8 & 7.9 & 2.9 & 8.7 & 2.6 \\
\hline Recognition (\% correct) & 97.6 & 4.4 & 97.1 & 2.9 & 96.7 & 4.5 \\
\hline
\end{tabular}

Note-BDI $=$ Beck Depression Inventory. SDMT $=$ Symbol Digit Modalities Test. STM $=$ Brown-Peterson short-term memory test. ${ }^{*} p<.05 \quad \dagger p<.01$. 
Significant differences among groups were also observed on the BDI and on both measures of anxiety $[F \mathrm{~s}(2,85)>37.83, p \mathrm{~s}<.001]$. Subsequent analyses showed that both patient groups differed from controls on all of these measures $(F \mathrm{~s}>47.09$, ps $<.001)$. In addition, the depressed patients had significantly higher scores on the BDI than the bulimics did $[F(1,44)=4.29$, $p<.05]$. Differences between patient groups on the anxiety scales were not statistically significant $(F \mathrm{~s}<3.77$, ps $>$.05).

A multivariate analysis of variance (MANOVA) that included all of the cognitive variables listed in Table 1 revealed significant differences among groups [Wilks Lambda $F(26,146)=2.00, p<.01]$. Subsequent univariate analyses revealed significant differences among groups on all trials of the free recall task $[F \mathrm{~s}(2,85)>3.45, p \mathrm{~s}<.05]$, on the fluency for famous people test $[F(2,85)=6.38, p<.01]$, and in the number of rule violations committed on the design-fluency task $[F(2,85)=3.68, p<.05]$. Pairwise comparisons on these measures demonstrated that both patient groups differed from controls on the recall and fluency for famous people tasks $(F \mathrm{~s}>5.02$, $p \mathrm{~s}<.05)$, but differences between patient groups on these measures were not significant $(F \mathrm{~s}<1)$. A different pattern was evident for rule violations. Bulimics made significantly more rule violations than controls did $[F(1,72)=5.19, p<.05]$, and they tended to make more rule violations than depressed patients did $[F(1,44)=2.89, p<.10]$. Controls and depressed patients did not differ on the rule-violation measure.

To measure retention over the 30 -min delay, we derived a savings score (number of words recalled on the delay trial/number of words recalled on Trial 4). Savings scores averaged 0.897 for controls, 0.823 for depressed patients, and 0.875 for bulimics). These differences were not significant $(F<2)$.

Differences among groups on the other dependent variables did not attain significance $\left[F_{\mathrm{s}}(2,85)<2.40\right.$, ps $>.05]$. Thus, on the verbal (letters, categories) and nonverbal (designs) fluency tasks, bulimic and depressed patients generated as many correct words and designs as did controls, and they recalled as many words as controls did on the STM test. These patients also performed normally on the SDMT, both in terms of the number of correct substitutions of numbers for digits and in the number of errors. Finally, depressed and bulimic patients recognized as many words after a delay as did controls.

To examine the relationship between severity of depression and cognitive impairment in bulimia, we divided the bulimic patients into two subgroups: more severely depressed bulimics $(N=17)$, who scored above 20 on the BDI $(M=31.3)$, and less severely depressed bulimics $(N=15)$, who scored 20 or below on the BDI $(M=$ 13.9). Comparison of the performance of these two subgroups with that of the controls showed that both the more and the less severely depressed bulimics made more rule violations on the design-fluency test and named fewer famous people than controls did ( $p s<.05)$, but only the more severely depressed bulimics were impaired on the free recall task. The results of these analyses should be interpreted cautiously, since the two bulimic subgroups did not differ significantly on any measure and only 3 bulimic patients scored below 10 on the BDI (the lower cutoff point for mild depression on this scale).

\section{DISCUSSION}

The present findings demonstrate that outpatient women with bulimia nervosa and those with major depression manifest impairments in anterograde learning and recall of verbal material and in generating the names of famous people. Bulimics, but not depressed patients, also exhibit increases in rule violations on the design-fluency task. Since impairments in the recall of newly acquired information have been observed in depressed inpatients (Clev et al., 1986; Fromm \& Schopflocher, 1984; Weingartner et al., 1981) and in the depressed outpatients in this study, it is possible that depression and/or associated negative affective states (e.g., high anxiety) may be responsible for the bulimic patients' poor performance on this task. This possibility is supported by our observation that only the severely depressed bulimic subjects perform more poorly than controls on this task. The ability to generate names on the fluency for famous people test favors the adoption of the strategy of selecting a category (e.g., movie stars) well known to the subject. Since both groups of patients performed normally on the letter- and categoryfluency tests, in which the appropriate "strategy" is provided by the experimenter, their difficulties in naming famous people are not likely to reflect general loss of access to semantic information of the sort that occurs in both cortical and subcortical dementias (see Butters, Salmon, Heindel, \& Granholm, 1988). This deficit may reflect a previously unrecognized cognitive impairment characteristic of both depression and bulimia. Among bulimics, difficulties in generating the names of famous people appeared to be unrelated to the level of depression as judged by BDI scores. Additional studies with larger patient samples and measures that require self-generated searches of semantic memory will be required to determine the generality of these findings.

We observed only one difference between the patterns of cognitive performance in our bulimic and our depressed patients. Bulimic, but not depressed subjects, showed an increase in the number of rule violations on the design-fluency test. Perhaps this finding represents a neuropsychological index of poor impulse control, which is regarded by many workers as characteristic of bulimia (Heilbrun \& Bloomfield, 1986; Johnson \& Connors, 1987; Norman \& Herzog, 1983). Our previous finding that children with attention deficit hyperactivity disorder, a condition characterized by impulsivity, exhibit similar increases in the number of rule violations on the design-fluency test (Loge, Staton, \& Beatty, in press) is consistent with this speculation.

Disturbances in attention among depressed inpatients have been reported in previous studies (Breslow et al., 1980; Reisberg et al,. 1982; Stromgren, 1977), but we found no evidence of impairment on the SDMT, a test of information-processing speed which is subject-paced. Since the attentional impairments of depressed patients are more evident when the experimenter controls the presentation of information (as, e.g., on vigilance tasks; see Raskin, 1986), this parameter may be important. Alternatively, attentional disturbances may be mild and difficult to detect in outpatient samples of depressed patients.

In the present study, both depressed and bulimic patients showed impaired recall but normal recognition of a list of unrelated words. These findings with outpatients, which are qualitatively similar to the results of earlier studies of verbal memory in depressed inpatients (Weingartner et al., 1981), may suggest that the patients' memory deficits arise primarily from difficulties in retrieving information. It should be noted, however, that both the depressed and bulimic patients exhibited deficits on the first immediate recall trial, which raises the possibility that defective encoding may cause this memory impairment. A major defect in 
memory storage mechanisms can probably be ruled out, since such a deficit would predict more rapid forgetting by the patients, which we did not observe.

The association of impaired recall with normal recognition memory in depressed subjects is considered evidence that the cognitive deficits in depression involve impairment of effortful as opposed to automatic processes (Cohen, Weingartner, Smallberg, Pickar, \& Murphy, 1982; Roy-Byme, Weingartner, Bierer, Thompson, \& Post, 1986; Weingartner et al., 1981). The present finding of impaired performance on the fluency for famous people task but normal output on the letter- and categoryfluency tests is consistent with this view. Our depressed and bulimic patients performed normally on the relatively difficult version of the Brown-Peterson STM test used in the present study, however-a test that seems just as effortful as the free recall task. Furthermore, both depressed and bulimic patients produced a normal number of novel designs. It is difficult to imagine what "automatic" process the designfluency task might engage. Therefore, these findings are only partially consistent with the hypothesis that depression is associated with the impairment of effortful task processing.

\section{REFERENCES}

Beck, A. T., Ward, C. H., Mendelson, M., Mock, J., \& ERBAUGH, J. (1961). An inventory for measuring depression. Archives of General Psychiatry, 4, 561-571.

BRAND, N., \& Jolles, J. (1987). Information processing in depression and anxiety. Psychological Medicine, 17, 145-153.

Breslow, R., Kocsis, J., \& BeLKIN, B. (1980). Memory deficits in depression: Evidence using the Wechsler Memory Scale. Perceptual \& Motor Skills, 51, 541-542.

Butters, N., Salmon, D. P., Heindel, W. C., \& Granholm, E. (1988). Episodic, semantic and procedural memory: Some comparisons of Alzheimer's and Huntington's disease patients. In R. Terry (Ed.), Aging and the brain (pp. 63-88). New York: Raven Press.

Clev, A., Korin, Y., Shapira, B., Kugelmass, S., \& Lerer, B. (1986). Verbal and non-verbal recall by depressed and euthymic affective patients. Psychological Medicine, 16, 789-794.

Cohen, R. M., Wiengartner, H., Smallberg, S. A., Pickar, D., \& MURPHY, D. L. (1982). Effort and cognition in depression. Archives of General Psychiatry, 39, 593-597.

Frith, C. D., Stevens M., Johnstone, E. C., Deakin, J. W. F., LAWLER, P., \& CROW, T. J. (1983). Effects of ECT and depression on various aspects of memory. British Journal of Psychiatry, 142, 610-617.

Fromm, D., \& SChOPflocher, D. (1984). Neuropsychological test performance in depressed patients before and after drug therapy. Biological Psychiatry, 19, 55-72.

Hart, R. P., \& KWentus, J. A. (1987). Psychomotor slowing and subcortical-type dysfunction in depression. Journal of Neurology, Neurosurgery \& Psychiatry, 50, 1263-1266.

Heilbrun, A. B., \& Bloomfield, D. L. (1986). Cognitive differences between bulimic and anorexic females: Self-control deficits in bulimia. International Journal of Eating Disorders, 5, 209-222.

Johnson, C., \& Connors, M. E. (1987). The etiology and treatment of bulimia nervosa: A biopsychosocial perspective. New York: Basic Books.

LeE, N. F., RuSh, A. J., \& MrTChell, J. E. (1985). Bulimia and depression. Journal of Affective Disorders, 9, 231-238.
Loge, D. V., Staton, R. D., \& Beatty, W. W. (in press). Performance of children with attention deficit hyperactivity disorder on tests sensitive to frontal lobe dysfunction. Journal of the American Academy of Child \& Adolescent Psychiatry.

McKay, S. E., Humphries, L. L., Allen, M. E., \& Clawson, D. R. (1986). Neuropsychological test performance of bulimic patients. International Journal of Neuroscience, 30, 73-80.

NIEDEREHE, G. (1986). Depression and memory impairment in the aged. In L. W. Poon (Ed.), Handbook for clinical memory assessment of older adults (pp. 226-237). Washington, DC: American Psychological Association.

Norman, D. K., \& Herzog, D. B. (1983). Bulimia, anorexia nervosa and anorexia nervosa with bulimia: A comparative analysis of MMPI profiles. International Journal of Eating Disorders, 2, 43-52.

RASKIN, A. (1986). Partialing out the effects of depression and age on cognitive functions: Experimental data and methodologic issues. In L. W. Poon (Ed.), Handbook for clinical memory assessment of older adults (pp. 244-256). Washington, DC: American Psychological Association.

Raskin, A., Friedman A. S., \&iMascio, A. (1982). Cognitive and performance deficits in depression. Psychopharmacology Bulletin, 18, 196-202.

Reisberg, B., Ferris, S. H., Georgotas, A., Deleon, M., \& SCHNECK, M. K. (1982). Relationship between cognition and mood in geriatric depression. Psychopharmacology Bulletin, 18, 191-193.

Roy-Byrne, P. P., Weingartner, H., Bierer, H., Thompson, L., \& Post, R. M. (1986). Effortful and automatic cognitive processes in depression. Archives of General Psychiatry, 43, 265-267.

Savard, R. J., ReY, A. C., \& Post, R. M. (1980). Halstead-Reitan Category Test in bipolar and unipolar affective disorders: Relationship to age and phase of illness. Journal of Nervous \& Mental Disease, 168, 297-304.

Silberman, E. K., Weingartner, H., \& Post, R. M. (1983). Thinking disorder in depression. Archives of General Psychiatry, 40, 775-780.

Smith, A. A. (1973). Symbol Digit Modalities Test manual. Los Angeles: Western Psychological Services.

Spielberger, C. D., Gorsach, R. L., \& Lushene, R. E. (1970). Manual for the State-Trait Anxiety Inventory. Palo Alto, CA: Consulting Psychologists Press.

Staton, R. D., Wilson, H., \& Brumback, R. A. (1981). Cognitive improvement associated with tricyclic antidepressant treatment of childhood major depressive disorder. Perceptual \& Motor Skills, 53, 219-234.

STERnberG, D. E., \& JARViK, M. E. (1976). Memory functions in depression: Improvement with antidepressant medication. Archives of General Psychiatry, 33, 219-224.

STromgren, L. S. (1977). The influence of depression on memory. Acta Psychiatrica Scandinavica, 56, 109-128.

Touyz, S. W., Beaumont, P. J. V., Johnstone, L. C. (1986). Neuropsychological correlates of dieting disorders. International Journal of Eating Disorders, 5, 1025-1034.

Weingartner H., Cohen, R. M., Murphy, D. C., Martello, J., \& GERDT, C. (1981). Cognitive processes in depression. Archives of General Psychiatry, 38, 42-47.

(Manuscript received November 20, 1989.) 